\title{
Gestión de la seguridad y salud en el trabajo frente al Covid-19 en una empresa del sector pesquero peruano
}

\begin{abstract}
Occupational safety and health management of COVID-19 at a company in the Peruvian fishing sector
\end{abstract}

Daniel Anderson Solorzano-Aquino ${ }^{1}$ (1) 0000-0003-4936-1600

Williams Esteward Castillo-Martínez' (i) 0000-0001-6917-1009

Guillermo Segundo Miñan-Olivos² ${ }^{2}$ 0000-0001-9523-8043

Wilson Daniel Símpalo-López 1 (1) 0000-0002-8397-7145

'Escuela de Ingeniería Industrial, Facultad de Ingeniería, Universidad Cesar Vallejo, Chimbote, Perú.

${ }^{2}$ Coordinación de Ciencias, Facultad de Ingeniería, Universidad Tecnológica del Perú, Chimbote, Perú.

Fechas · Dates

Recibido: 2021.03.02

Aceptado: 2021.06.25

Publicado: 2021.07.15
Correspondencia · Corresponding Author

Guillermo Segundo Miñan-Olivos

Correo electrónico: c20342@utp.edu.pe 


\title{
Resumen
}

Objetivo: Evaluar la gestión de seguridad y salud en el trabajo de una empresa del sector pesquero peruano frente al Covid-19

Métodos: La variable independiente fue la gestión de seguridad y salud en el trabajo respecto a la implementación de acciones preventivas y de control frente al Covid-19. La variable dependiente se midió a través del número de casos detectados y la tasa de positividad de Covid-19. Se utilizó un diseño preexperimental con una preprueba, durante la implementación en proceso y una post prueba, con información recopilada al finalizar las acciones preventivas y de control. Se realizó un análisis inferencial no paramétrico para establecer diferencias significativas entre la preprueba y la post prueba y el grado de asociación entre las variables.

Resultados: La empresa inició una estrategia de detección de casos positivos a través del uso de pruebas serológicas. Durante la primera etapa, se realizaron 2329 pruebas que arrojaron un $71 \%$ de positividad. Una vez que se implementaron las acciones de prevención y control la tasa de positividad se redujo a un 15.65\% durante agosto del 2020. Las pruebas inferenciales mostraron un nivel de significación ( $p<0.05)$ en la reducción obtenida, así como en la relación de esta con las medidas adoptadas.

Conclusiones: Una adecuada gestión de seguridad y salud en el trabajo frente al Covid-19 redujo de manera significativa el número de casos detectados y la tasa de positividad del Covid-19 en trabajadores del sector pesquero peruano.

Palabras clave: Covid-19; seguridad ocupacional; salud en el trabajo.

\begin{abstract}
Objective: To evaluate the occupational safety and health management of COVID-19 at a company in the Peruvian fishing sector
\end{abstract}

Methods: The independent variable was occupational safety and health management, defined as the implementation of preventive and control measures in response to COVID-19. The dependent variable was defined as the number of detected COVID-19 cases and test positivity rate. We used a pre- (implementation phase) and post-test (following the implementation phase) study design. We performed a non-parametric inferential analysis to identify any significant pre- and post-test differences and any associations between the variables.

Results: The company initiated a strategy to detect positive cases through the use of serological tests. During the first stage, 2329 tests were conducted, yielding a positivity rate of $71 \%$. Once prevention and control actions were implemented, the positivity rate in August 2020 had decreased to $15.65 \%$, a statistically significant decrease $(p<0.05)$, as well as its relationship to the measures implemented.

Conclusions: This occupational safety and health intervention significantly reduced the number of COVID-19 cases and positivity rate in this group of workers in the Peruvian fishing sector.

Keywords: COVID-19; occupational safety; health at work. 


\section{Introducción}

En el Perú, la pandemia producida por el Covid-19 ha tenido un impacto sumamente importante tanto en el sector salud como en el ámbito económico. Al haber alcanzado los 198 días de emergencia sanitaria la cifra de casos positivos ya se acercaba al millón, lo que a su vez representaba 22941 casos por cada millón de habitantes ${ }^{(1)}$. De la misma manera, el contexto inicial de la pandemia generó el cierre temporal de muchas actividades productivas y empresariales. Posteriormente, el gobierno peruano inició un plan de reactivación económica progresivo con la finalidad de mitigar el impacto socioeconómico que se venía presentando. Ante dichas limitaciones, el sector pesquero peruano tuvo la ventaja de continuar sus operaciones productivas al ser considerado como un sector básico para evitar el desabastecimiento de alimentos dirigidos hacia la población. La producción de productos frescos se vio impactada pero lo contrario sucedió en la oferta de congelados, asimismo, se observó un incremento en la demanda de conservas, marinados y ahumados, por ser alternativas con una elevada vida útil(2). La continuidad de las operaciones supuso un reto para las empresas del sector pesquero peruano ya que se afrontaba una enfermedad altamente contagiosa, de la cual se conocía muy poco y que debía fomentar un cambio de hábitos y conductas de los trabajadores. La gestión de seguridad y salud en el trabajo se convirtió en un eje clave de toda empresa para evitar la propagación del virus durante las jornadas laborales. El presente trabajo evalúa el efecto de la gestión en seguridad y salud en el trabajo sobre los contagios de Covid-19 en una empresa del sector pesquero peruano.

\section{Métodos}

Se aplicó un diseño preexperimental con una preprueba y una post prueba. Asimismo, los resultados obtenidos permitieron que el estudio tuviera un alcance tanto descriptivo como explicativo. La población de estudio estuvo conformada por todos los trabajadores de la empresa, mientras que la muestra se conformó por todos los trabajadores que fueron sometidos a pruebas de descarte. El muestreo fue no probabilístico sino por conveniencia ya que los trabajadores fueron seleccionados por la presencia de síntomas, por contacto con alguna persona infectada, por alguna condición física o al reingreso laboral. Los trabajadores incluidos en el estudio formaban parte de áreas operativas y administrativas, con una relación laboral a plazo indeterminado, con edades entre 25 y 68 años y con ingresos que oscilaban entre 294 y 1470 dólares mensuales. El diseño general fue el siguiente:

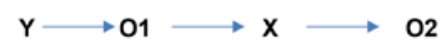

Y representa el grupo de estudio, que para la presente investigación estuvo conformado por todos los trabajadores de la empresa. 01 representa la observación inicial o preprueba sobre el nivel de contagios de Covid-19 en trabajadores de la empresa. X representa la gestión realizada en el área de seguridad y salud en el trabajo para reducir los peligros y riesgos asociados al contagio de Covid-19 en la 
empresa. 02 representa la observación final o post prueba sobre el efecto obtenido en el nivel de contagios de Covid-19 en trabajadores de la empresa

Se diseñaron distintas acciones que luego fueron ejecutadas como parte de la estrategia adoptada en seguridad y salud en el trabajo. Como primer punto, se procedió a actualizar los peligros y riesgos existentes en la empresa para lo cual se hizo uso del mapa de riesgos y de la matriz de Identificación de Peligros, Evaluación de Riesgos y Medidas de Control. En segundo lugar, al ser una enfermedad reciente, se resaltó la importancia de sensibilizar y capacitar a los trabajadores respecto a los conceptos del Covid-19 y a las medidas de prevención que debía adoptar cada persona. Como tercera acción, se estipuló el cumplimiento de la normativa legal establecida por el estado peruano la cual se difundió a través de la Resolución Ministerial 239-2020-MINSA, publicada el 28 de abril del 2020. En última instancia, se implementó un sistema de control para la detección del Covid-19 a través de la aplicación de pruebas serológicas diarias al considerar los siguientes criterios: sospecha de contagio por sintomatología (fiebre, tos, entre otros), exposición a un caso positivo o antes del retorno al puesto de trabajo. Debido a que el estudio ha considerado varios meses de observación, en el caso de los trabajadores que previamente ya hubiesen dado positivo en una prueba serológica, se procedía a confirmar la información mediante una prueba molecular (PCR) para que de esa manera se evitáse algún tipo de sesgo en el estudio o algún tipo de error en el registro de los casos positivos, como la detección de inmunoglobulinas IgG tras haber superado la infección; es decir, que en dicha situación el registro del caso positivo solo debía darse por una reinfección.

Para la actualización de peligros y riesgos en la empresa, se utilizó como técnica de investigación la identificación de peligros y evaluación de riesgos. Dicha técnica se aplicó a través de dos instrumentos: la Matriz IPERC y el Mapa de Riesgos. En el diseño de la Matriz IPERC se consideró la presencia del Covid-19 como un peligro biológico por exposición o contacto con personas infectadas, equipos, materiales, objetos o parte de las instalaciones de la empresa. Para el riesgo asociado a dicho peligro, se tomó en cuenta al contagio de Covid-19 causante de una infección respiratoria con desenlace en una enfermedad pulmonar, neumonía o la muerte. Los protocolos de seguridad se iniciaron con la limpieza y desinfección de los puestos de trabajo, se redujo el aforo de algunas zonas y se delimitaron los espacios para asegurar el distanciamiento social. De la misma manera, se implementaron puntos de desinfección en zonas estratégicas, para asegurar que los trabajadores cumplieran con la obligatoriedad del lavado de manos. En el caso de los equipos de protección personal, se incluyó el uso obligatorio de las mascarillas tanto para trabajadores operativos como administrativos. Para el ingreso a las instalaciones, se estableció como pauta obligatoria la medición de la temperatura corporal. Se identificaron los trabajadores con distintas condiciones o padecimientos médicos que los ubicaban en un contexto de alto riesgo y en una situación de vulnerabilidad frente al Covid-19; en ese sentido, se registraron los trabajadores con las siguientes características: mayores de 65 años, con hipertensión arterial, con diabetes, obesidad (IMC superior a 40), cáncer y otras enfermedades graves o crónicas (cardiovasculares, pulmonares, renales, entre otras). En concordancia con ello, el área 
de seguridad y salud en el trabajo implementó un sistema de vigilancia permanente de comorbilidades.

En el caso de la sensibilización y capacitación de los trabajadores sobre la Covid-19, se llevaron a cabo talleres de sensibilización y capacitación que fueron monitoreados a través de un control de asistencia estricto. Dichos talleres se enfocaron en conocer sobre la enfermedad en sí y sobre las medidas de prevención que se debían adoptar dentro de la empresa y fuera de la misma. Implementación del Plan de vigilancia, prevención y control de la Covid-19 en el trabajo: para dicha implementación, se tomó en cuenta la normativa legal peruana expuesta en la Resolución Ministerial 239-2020-MINSA, la cual planteaba lineamientos para el sistema de seguridad y salud en el trabajo, procedimientos obligatorios de prevención, procedimientos para el regreso o reincorporación al trabajo, entre otros.

Detección de contagios por Covid-19: la detección de casos positivos se llevó a cabo mediante el uso de pruebas serológicas. Las pruebas serológicas se pueden definir como exámenes inmunocromatográficos de fácil aplicación para detectar anticuerpos contra el virus; sin embargo, debido a la complejidad de la sintomatología de la Covid-19, las pruebas serológicas de IgG e IgM especificas a SARSCoV-2 no fueron pruebas definitivas de diagnóstico sino herramientas complementarias ${ }^{(3)}$, las cuales fueron utilizadas en la gestión de seguridad y salud en el trabajo de la empresa. Para medir la efectividad de las acciones implementadas, se utilizaron los siguientes indicadores: Nivel de seguimiento Covid-19 (número de pruebas diarias), tasa de positividad Covid-19 (porcentaje diario de casos positivos en prueba serológica) y el valor nominal de contagio por Covid-19 (número de casos detectados por Covid-19)

Para el análisis de los datos, inicialmente se evaluó la normalidad de los datos a través de una Prueba de Kolmogorov-Smirnov. La información recopilada no presentó una distribución normal y es por ello por lo que se empleó un análisis inferencial no paramétrico para evaluar dos aspectos: la reducción de casos positivos por Covid-19 y la relación existente entre dicha reducción con la medidas implementadas. Se utilizó SPSS 25 para realizar una Prueba de la mediana para muestras independientes que determinó si existía una diferencia estadísticamente significativa entre el número de contagiados y la tasa de positividad al comparar los resultados durante la preprueba y la post prueba. De la misma manera, se aplicó una Prueba Chi-cuadrado de Pearson para evaluar la asociación o relación entre los niveles de la gestión desarrollada (en proceso y completada) y los niveles de la positividad por Covid-19 (bajo, medio y elevado). Se consideró que la gestión estaba en proceso durante los primeros 34 días de la investigación y completa durante los 80 días siguientes. Los niveles de positividad tuvieron la siguiente escala: $<20 \%$ = bajo, entre el $20 \%$ y $50 \%$ = medio y $>50 \%=$ elevado.

\section{Resultados}

El análisis de preprueba evaluó la situación antes de que se logren implementar completamente todas las acciones planteadas en temas de seguridad y salud en 
el trabajo frente al Covid-19. La detección de contagios fue la primera acción inmediata que se tomó para limitar la propagación de la enfermedad en los puestos de trabajo. En la Figura 1 se muestran las pruebas diarias que se realizaron durante el periodo del 26-03-20 al 15-05-20, las cuales fueron un total de 2329 pruebas con un promedio diario de 69 pruebas.

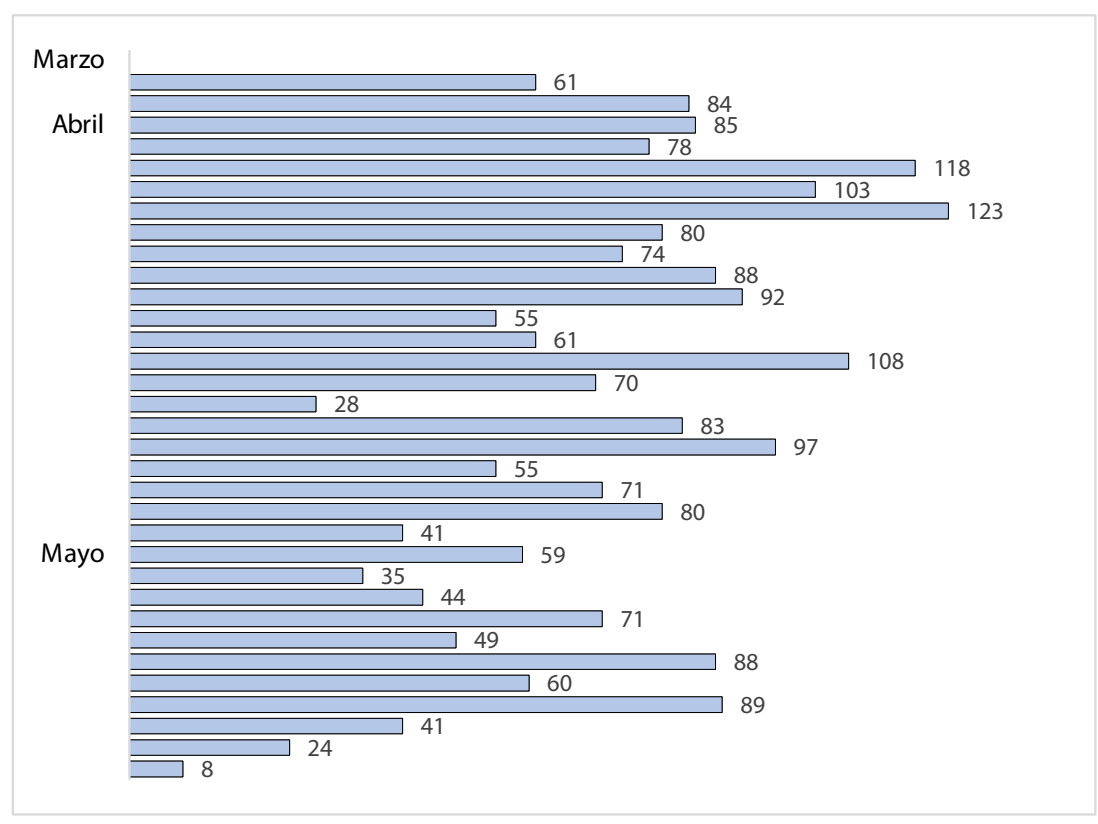

Figura 1: Nivel de seguimiento Covid-19 a través de la aplicación de pruebas serológicas durante el periodo del 26-03-20 al 15-05-20

En la Figura 2 se puede notar que en los primeros días la tasa de positividad era muy alta. Durante la primera semana fue del $77.01 \%$ y recién en la segunda semana de mayo se puede apreciar que el promedio móvil mostraba una tendencia a la baja donde se obtuvo una media semanal del 37.01\% desde el 08-05-20 hasta el 15-05-20 


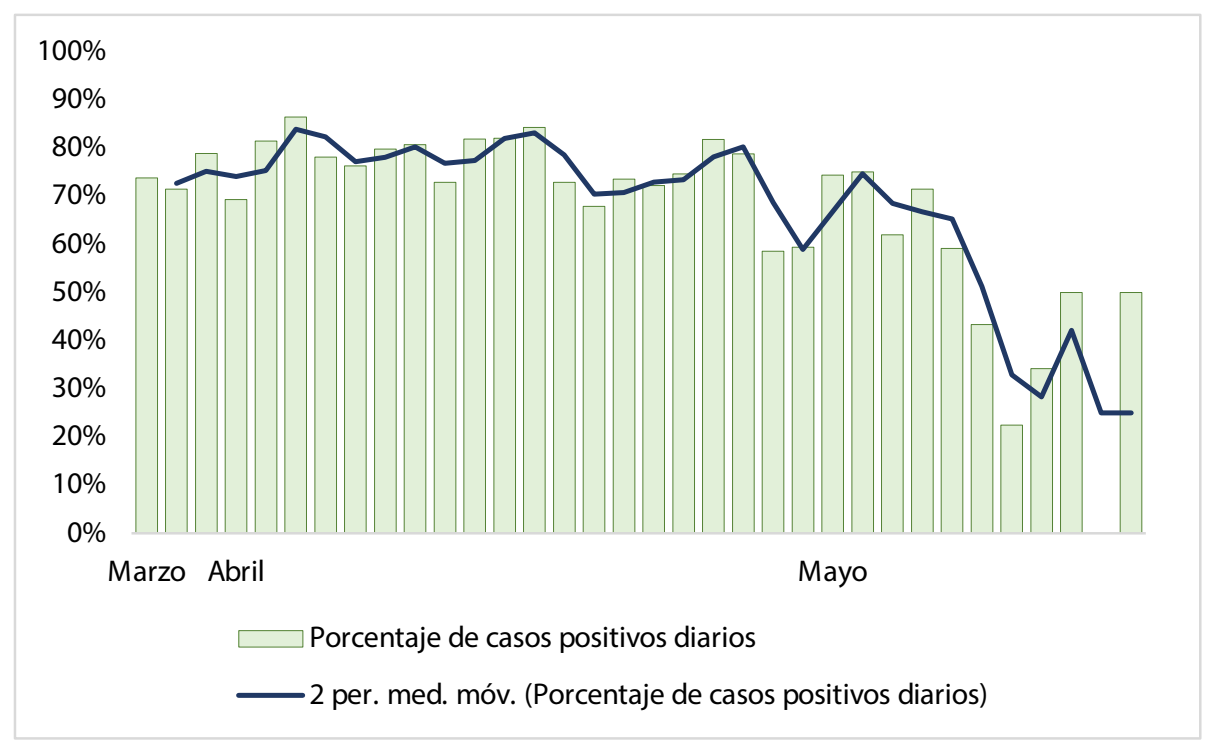

Figura 2: Tasa de positividad Covid-19 diaria durante el periodo del 26-03-20 al 15-05-20

Por otro lado, a través de la Figura 3 se puede determinar que durante la fase de implementación de acciones preventivas frente al Covid-19, se detectaron un total de 1648 casos reactivos ( $\mathrm{gg} / \mathrm{lgM}$ ) equivalente al $71 \%$ de las pruebas realizadas.

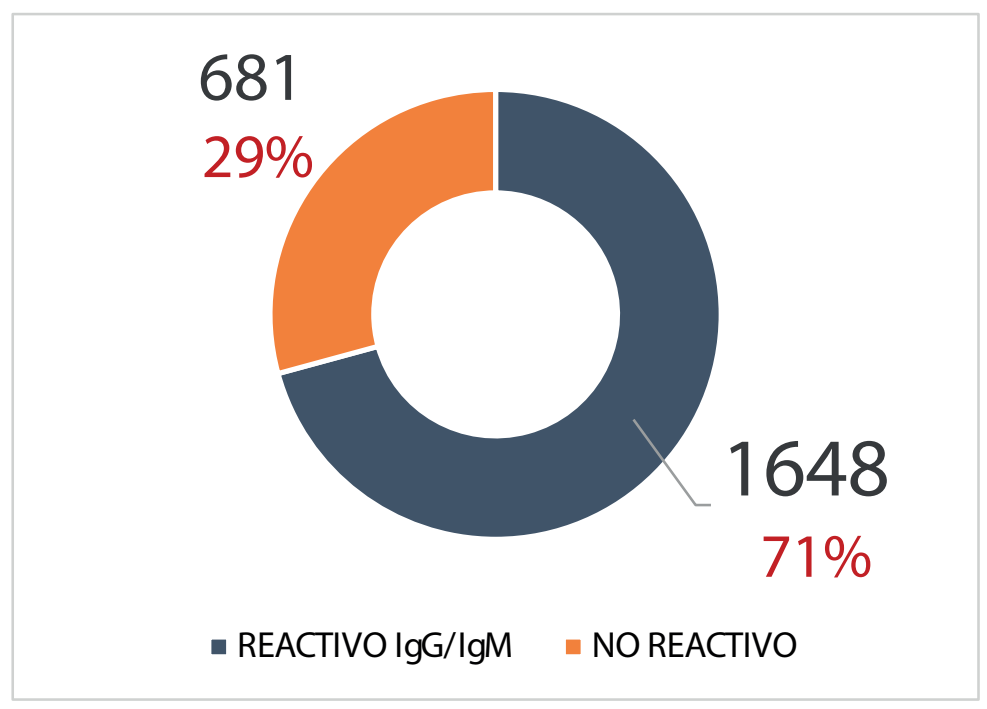

Figura 3: Casos detectados por Covid-19 durante el periodo del 26-03-20 al 15-05-20

Luego de haber implementado las acciones descritas en el apartado de métodos, se continuo con la cuantificación de los indicadores contemplados. En la Figura 4 se puede observar el número de pruebas serológicas realizadas en las dos etapas 
de investigación y el comportamiento diario de la tasa de positividad en la fase de post prueba.

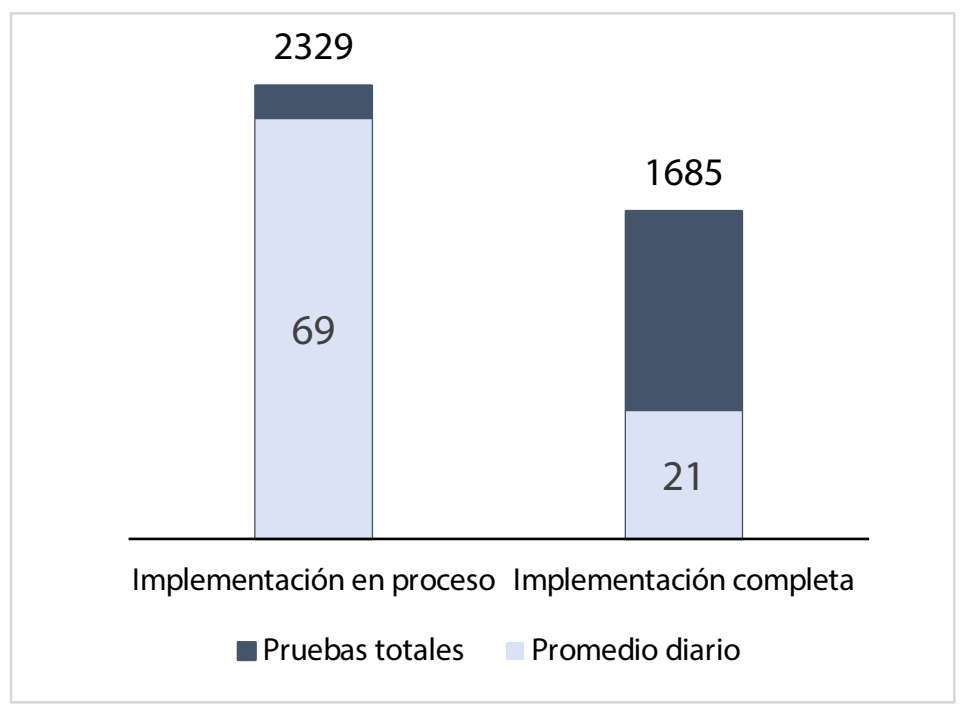

Figura 4a: Pruebas serológicas

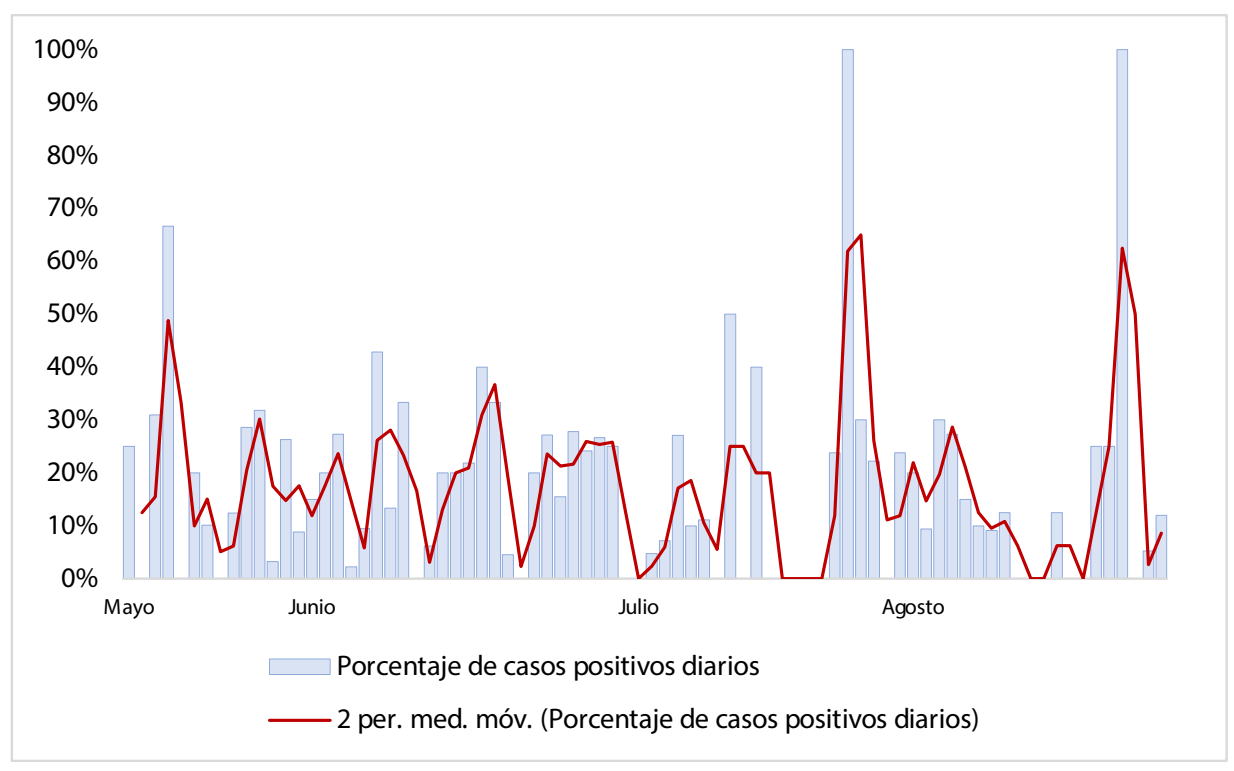

Figura 4b: Tasa de positividad durante 16-05-20 hasta el 31-08-20

Figura 4: Indicadores del sistema de seguridad y salud en el trabajo luego de la implementación de acciones preventivas y de control frente al Covid-19

En la Figura 4a se observa que la cantidad de pruebas realizadas disminuyó luego de haberse completado la implementación de mejoras en el sistema de seguridad 
y salud en el trabajo. En la etapa inicial se realizaron 2329 pruebas a un promedio diario de 69 durante 34 días, mientras que; posteriormente, dicha cantidad descendió a 1685 pruebas con una media diaria de 21 durante 80 días. Es decir, las pruebas serológicas tuvieron una reducción del $27.65 \%$. Respecto a su aplicación diaria, la reducción fue del $69.57 \%$ en contraste con el periodo inicial de la emergencia sanitaria.

Si se observa la Figura 3, la tendencia empezaba a disminuir al culminar la primera quincena de mayo. En la Figura 4b, se muestra el comportamiento diario de la tasa de positividad durante el periodo correspondiente del 16-05-20 al 31-08-20. Se puede observar una caída en el porcentaje de casos positivos detectados diariamente. Durante la segunda quincena de mayo la tasa de positividad diaria tuvo un promedio de $18.85 \%$. Para ese mismo periodo, el valor más alto de la tasa fue de $66.67 \%$. Para el mes de junio, la tasa de positividad presentó un valor promedio diario de $19.02 \%$, que demostraba un ligero incremento, pero cuyo valor máximo no había superado el $43 \%$. En el mes de julio, la tasa media diaria de positividad fue de $16.67 \%$ y se alcanzó un valor máximo del 100\% solo en un caso aislado donde se realizó una única prueba a un solo trabajador que dio positivo. Para el caso del mes de agosto, la tasa de positividad tuvo una media de $15.65 \%$ con un valor máximo del $100 \%$ pero al igual que el mes anterior, solo se presentó en un caso aislado. Asimismo, en dicho mes se registraron 6 días donde no se registró ningún caso positivo.

La Tabla 1 determina que tanto la mediana del número de contagiados diarios como la tasa de positividad diaria, presentaron una reducción significativa $(p<0.05)$ luego de haber implementado acciones de prevención y control frente al Covid-19. Asimismo, la Prueba Chi-cuadrado de Pearson estableció una asociación significativa $(p<0.05)$ entre la implementación de acciones de prevención y control frente al Covid-19 y los niveles de positividad diarios.

Tabla 1: Análisis inferencial de los resultados obtenidos respecto a la gestión de seguridad y salud en el trabajo frente al Covid-19

\begin{tabular}{|c|c|c|c|c|}
\hline \multicolumn{5}{|c|}{ Prueba de la mediana para muestras independientes } \\
\hline Variable & \multicolumn{3}{|c|}{ Hipótesis nula } & p-valor \\
\hline $\begin{array}{l}\text { Número de } \\
\text { contagiados diarios }\end{array}$ & \multicolumn{3}{|c|}{$\begin{array}{l}\text { La mediana diaria de contagiados no varió significativamente } \\
\text { luego de las acciones implementadas frente al Covid-19 }\end{array}$} & $0.00^{\mathrm{a}}$ \\
\hline $\begin{array}{l}\text { Tasa de positividad } \\
\text { diaria }\end{array}$ & \multicolumn{3}{|c|}{$\begin{array}{l}\text { La mediana diaria de positividad no varió significativamente } \\
\text { luego de las acciones implementadas frente al Covid-19 }\end{array}$} & $0.00^{\mathrm{a}}$ \\
\hline \multicolumn{5}{|c|}{ Prueba Chi-cuadrado de Pearson (Tabla $3 \times 2$ ) } \\
\hline \multirow{2}{*}{$\begin{array}{l}\text { Implementación de } \\
\text { acciones }\end{array}$} & \multicolumn{3}{|c|}{ Niveles de positividad diaria } & \multirow[t]{2}{*}{ p-valo } \\
\hline & Bajo & Medio & Elevado & \\
\hline En proceso & 1 & 5 & 28 & $0.00^{\mathrm{a}}$ \\
\hline Completa & 44 & 33 & 3 & \\
\hline
\end{tabular}

a Significancia con un nivel de confianza del $95 \%$ 


\section{Discusión}

Toda empresa debe garantizar las condiciones adecuadas para que sus empleados o trabajadores puedan desarrollar sus actividades sin poner en riesgo su integridad física o salud. En el caso de trabajadores sanitarios la situación resulta más clara por su exposición directa con personas contagiadas y considerar la Covid-19 como enfermedad profesional resulta lógico(4). En el Perú, se promulgó la ley $N^{\circ} 31025$ que incluye a la Covid-19 como enfermedad ocupacional en el sector salud, pero a pesar de que dicha ley no involucra al sector empresarial, la omisión de los protocolos de seguridad establecidos por el gobierno si pudiese incurrir en consecuencias legales ${ }^{(5)}$. Al respecto, el presente estudio cumplió con lo establecido por la Resolución Ministerial 239-2020-MINSA, publicada el 28 de abril del 2020, actualizó sus instrumentos de seguridad y salud en el trabajo (matriz IPERC y mapa de riesgo) y ha cumplido con las capacitaciones contempladas por la ley $N^{\circ} 29783$; en ese sentido, los resultados de la investigación evidencian un apego de la empresa por la normativa vigente con resultados favorables en la protección a sus trabajadores. Asimismo, la evidencia estadística (Prueba Chi-cuadrado de Pearson) confirmó que la implementación descrita tuvo una asociación con la reducción de contagios por Covid-19 en la empresa.

También cabe destacar, que generalmente las empresas pesqueras están más familiarizadas con una gestión ocupacional enfocada en peligros del tipo ergonómico, físico, entre otros ${ }^{(6)}$. Sin embargo, adicionalmente a las estrategias propias de un sistema de seguridad y salud en trabajo, en la coyuntura vigente, se ha visto necesario fortalecer estrategias de vigilancia y mantenimiento que permitan sostener en el tiempo, las medidas y acciones de prevención destinadas a evitar los contagios por Covid-19(7). En el presente estudio, dichas estrategias se enfocaron en la supervisión de nuevos equipos de protección personal como el uso de mascarillas para cada trabajador, en el distanciamiento social obligatorio, una constante desinfección de las manos, en la aplicación de pruebas serológicas, entre otras medidas. La eficacia de dichas estrategias se evidenció en una reducción, estadísticamente significativa (Prueba de la mediana para muestra independientes), de los contagios por Covid-19.

En el caso de la utilización de pruebas combinadas de lgM e lgG rápidas, no se recomienda su aplicación para diagnósticos clínicos individualizados, pero son viables en sistemas de salud ocupacional y de vigilancia epidemiológica( ${ }^{(8)}$. Asimismo, las pruebas serológicas rápidas pueden lograr un nivel de detección superior si se compara con las pruebas moleculares, sobre todo durante la segunda semana de sintomatología ${ }^{(9)}$. En el presente estudio, los resultados demuestran que las pruebas serológicas permitieron la implementación de un plan de seguimiento a la pandemia dentro de las instalaciones de la empresa, al mismo tiempo, cumplieron un rol de alerta ante posibles casos positivos que requerían aislamiento del trabajador y evaluación de personas con contacto directo.

Un estudio realizado sobre trabajadores del Aeropuerto Internacional El Dorado de Bogotá, empleó la RT-PCR (reacción en cadena de la polimerasa con transcriptasa inversa) y la prueba serológica para la detección del Covid-19. Los hallazgos del 
estudio lograron identificar a 35 trabajadores como casos positivos de Covid-19 de un total de 212 , es decir, la incidencia o positividad fue del 16.51\%(10). Al inicio del presente estudio, la incidencia o positividad estuvo a una razón de 7 casos positivos por cada 10 pruebas realizadas (70\%). Esta elevada tasa de positividad se podría sustentar en que la empresa no detuvo sus operaciones durante la etapa inicial de la pandemia, lo cual trajo consigo el desarrollo de actividades con un bajo nivel de prevención. Para la etapa de post prueba, si se puede notar una similitud con los resultados del estudio previamente citado, ya que en agosto del 2020 la tasa de positividad tuvo un promedio de $15.65 \%$.

En conclusión, Perú es uno de los países más afectados por el Covid-19, a nivel de Sudamérica y en el mundo. En ese sentido, el avance de la pandemia ha causado diversas dificultades que han limitado el normal funcionamiento de muchas empresas peruanas. El sector pesquero ha sido uno de los pocos sectores que han continuado operando en plena emergencia sanitaria en el Perú, ya que representa una actividad básica para la sociedad. Sin embargo, la continuidad productiva solo se podía garantizar mediante una eficaz gestión de la seguridad y salud en el trabajo.

En la presente investigación, se ha demostrado la importancia de diseñar e implementar acciones preventivas y de control frente al Covid-19. Actualizar los mecanismos de identificación de peligros y evaluación de riesgos genera que los sistemas de seguridad y salud en el trabajo puedan implementar estrategias destinadas a garantizar la integridad de los trabajadores. De la misma manera, la sensibilización y capacitación del personal ha resultado crucial para que los trabajadores eviten las acciones inseguras que los expongan a posibles contagios. Por otro lado, el cumplimiento de la normativa legal peruana facilitó la implementación de protocolos para el desarrollo de las jornadas laborales, así como para casos de reincorporación laboral, y la utilización de pruebas serológicas sirvió como herramienta de seguimiento y de contención ante la propagación del virus. Finalmente, se pudo concluir que la empresa pesquera estudiada desarrolló una adecuada gestión de seguridad y salud en el trabajo frente al Covid-19, reduciendo de manera significativa el número de casos detectados y, por correspondiente, la tasa de positividad.

\section{Bibliografía}

1. Huamani N, Orozco J. Análisis comparativo y proyección por millón de habitantes de contagio y muerte por covid-19 en Sudamérica. Ciencia y Tecnología: Revista de la Universidad de Costa Rica. 2021;37(1):37-44.

2. Moreno-Salazar K, Lanchipa-Ale T, Luque-Zuñiga B. Seguridad alimentaria en tiempos de COVID-19: Una visión desde la cadena productiva de recursos hidrobiológicos. Estud desarro soc Cuba Am Lat. 2021;9(1):1-18.

3. Aguilar P, Enríquez Y, Quiroz C, Valencia E, León J, Pareja A. Pruebas diagnósticas para la COVID-19: la importancia del antes y el después. Horiz méd. 2020;20(2):1-7. 
4. Martí-Amengual G, Sanz-Gallen P, Arimany-Manso J. Valoración medicolegal de la infección por COVID-19 en el ámbito laboral. Rev esp med legal. 2020;46(3):146152.

5. Ubillus A. Responsabilidad penal del empleador ante el contagio de Covid-19 en el centro de trabajo - Lambayeque. Rev jurid cient SSIAS. 2020; 13(2):1-13.

6. Miñan-Olivos G, Monja-Palomo J, Gonzales-Pacheco O, Simpalo-Lopez W, Castillo-Martínez W. Gestión de riesgos implementando la ley peruana 29783 en una empresa pesquera. Ing Ind (La Habana). 2020;41(3):1-12

7. Moreno-Sueskun I, Díaz-González J, Acuña Juanbeltz A, Pérez-Murillo A, Garasa Jiménez A, García-Osés V, Extramiana Cameno E. Reincorporación al trabajo en el contexto de la pandemia de COVID-19 en sectores de industria y construcción en Navarra (España). Arch Prev Riesgos Labor. 2020;23(4):443-457.

8. Idrovo A, Moreno J, Pinzón C. Desempeño de las pruebas combinadas de IgM e IgG rápidas en la vigilancia ocupacional de COVID-19 en empresas colombianas. Biomédica. 2020;40(2):139-147.

9. Vidal-Anzardo M, Solis G, Solari L, Minaya G, Ayala-Quintanilla B, Astete-Cornejo $J$, et. al. Evaluación en condiciones de campo de una prueba serológica rápida para detección de anticuerpos IgM e IgG contra SARS-COV-2. Rev Peru Med Exp salud pública. 2020;37(2):203-209.

10. Malagón-Rojas J, Gómez-Rendón C, Parra E, Almentero J, Palma R, López R, et al. SARS-CoV-2 y RT-PCR en pacientes asintomáticos: resultados de una cohorte de trabajadores del Aeropuerto Internacional El Dorado de Bogotá, 2020. Biomédica. $2020 ; 40(2): 166-172$ 